\title{
Effect of Sewage Sludge Compost on Yield of Vegetable Crops
}

\author{
Young Bae Park* and Jae-Seung Noh \\ National Institute of Horticultural and Herbal Science RDA, Suwon 440-706, Korea
}

\begin{abstract}
Two phases of experiment were conducted to produce compost using sewage sludge and sawdust as mixing materials to determine their chemical properties and the performance of selected test crops. The first phase was done to produce compost as potting media and the second phase was done to test the efficacy of the produced compost. With regard to some chemical properties of the compost, $\mathrm{pH}$ was moderately acidic (5.11 to 5.58) while the $\mathrm{OM}, \mathrm{N}, \mathrm{P}$, and $\mathrm{K}$ contents of the compost were $23.8-35.9,1.12-1.56,254.9-555.7$, and 40.4-62.6, respectively.
\end{abstract}

Key words: pH, Sewage Sludge, Compost, Yield, Vegetables

\section{Introduction}

Organic fertilizers tend to be less concentrated in nutrients than inorganic fertilizers, and the nutrients in organic fertilizers are usually more slowly released. This means that larger amounts of organic fertilizers are needed, but their effects will last longer. Organic fertilizers are however not always balanced in nutrients, and it is more difficult to estimate how much to use compared to commercial fertilizers (Shrestha, 1996). Fortunately, when organic fertilizers are used, the environment is often benefited by recycling materials that would otherwise be wastes, and by saving the energy and natural resources required to make processed fertilizers, some of which involve composting. Composts that look woody are usually low in nitrogen. Like sawdust, they require additional nitrogen when mixed into the soil (Smith, 1986).

\section{Materials and Methods}

The solid sewage sludge obtained from the sanitary treatment plant and sawdust were used in the experiment. The sewage sludge was pulverized then mixed with sawdust. Turning of the compost piles was done weekly and it was watered regularly. Growth and yield of selected horticultural crops in compost of sewage sludge and

\footnotetext{
Received : December 29. 2010 Accepted : March 1. 2011

*Corresponding author : Phone: +82312403648

E-mail: ybpark6291@hanmail.net
}

sawdust were measured. The data were statistically analyzed using the analysis Variance (ANOVA). Physical and chemical properties of the sewage sludge are shown in Table 1.

\section{Results}

The properties of sewage sludge compost treated in soils are shown in Table 2. Increasing amount of sewage sludge treated in soils resulted in a decrease in waterholding capacity. On the other hand, increasing amount of sewage sludge mixed with sawdust increased waterholding capacity of a mixed media. With increasing amounts of sewage sludge $\mathrm{pH}$ of the compost was decreased. For organic matter content, 4:1 ratio of sewage sludge and sawdust showed the highest OM content among the treatment. The highest total nitrogen content was obtained from 2:1 ratio (1part of sewage sludge: 2 part of sawdust) while the lowest was recorded from 1:2 ratio of sewage sludge and sawdust. The highest phosphorus content was obtained from 1:1 ratio (1part of sewage sludge: 2 part of sawdust). The highest potassium content was obtained from was obtained from 4:1 parts of sewage sludge and sawdust.

The yield results of vegetables grown in mixtures of compost is also shown in Table 2. The yield of pechay was significant in 4:1 treatment. The yield of green onions was significant in 2:1 treatment. Yield of Bush Beans was the highest in a soil medium mixed with 1:3 part of sewage sludge and sawdust. 
Table 1. Physical and chemical propertiesof the sewage sludge compost.

\begin{tabular}{|c|c|c|c|c|}
\hline $\mathrm{pH}$ & $\mathrm{OM}$ & $\mathrm{T}-\mathrm{N}$ & $\mathrm{P}$ & $\mathrm{K}$ \\
\hline & -------" & ---------- & -------------- & ------------. \\
\hline 6.4 & 28.8 & 1.49 & 57.54 & 3.97 \\
\hline
\end{tabular}

Table 2. Chemical properties and relative yields of three vegetables for the treatments.

\begin{tabular}{|c|c|c|c|c|c|c|c|c|}
\hline \multirow{2}{*}{ Treatment $^{\dagger}$} & \multirow{2}{*}{$\mathrm{pH}$} & \multirow{2}{*}{$\mathrm{OM}$} & \multirow{2}{*}{$\mathrm{T}-\mathrm{N}$} & \multirow{2}{*}{$\mathrm{T}-\mathrm{P}$} & \multirow{2}{*}{$\mathrm{K}$} & \multicolumn{3}{|c|}{ Yield } \\
\hline & & & & & & Pechay & Green onions & Bush Beans \\
\hline & & \multicolumn{2}{|c|}{ 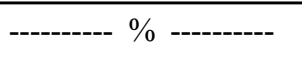 } & \multicolumn{2}{|c|}{---- $\mathrm{mg} \mathrm{kg}^{-1}$} & \multicolumn{3}{|c|}{--------------------- g pot ${ }^{-1}$--------------------- } \\
\hline $1: 1$ & 5.46 & $27.8 b c^{\ddagger}$ & $1.41 \mathrm{da}$ & $555.7 \mathrm{a}$ & $44.7 \mathrm{e}$ & $30.3 \mathrm{ca}$ & 129.03aba & $178 \mathrm{aa}$ \\
\hline $1: 2$ & 5.43 & $23.8 \mathrm{c}$ & $1.12 \mathrm{e}$ & $425.3 b$ & $44.2 \mathrm{f}$ & $33.7 \mathrm{c}$ & $91.4 \mathrm{ab}$ & $38 \mathrm{a}$ \\
\hline $1: 3$ & 5.37 & $27.8 \mathrm{bc}$ & $1.41 \mathrm{~d}$ & 401.1c & $49.4 b$ & $22.5 \mathrm{~d}$ & $80.6 \mathrm{~d}$ & $45 \mathrm{a}$ \\
\hline $1: 4$ & 5.58 & $30.9 \mathrm{abc}$ & $1.55 \mathrm{~d}$ & $388.1 \mathrm{a}$ & $48.9 \mathrm{c}$ & $37.2 \mathrm{c}$ & $46.2 \mathrm{~d}$ & $44 a$ \\
\hline $4: 1$ & 5.11 & $35.9 \mathrm{a}$ & $1.55 b$ & $388.8 \mathrm{a}$ & $62.6 \mathrm{a}$ & $102.8 \mathrm{ab}$ & $134.4 \mathrm{a}$ & $22 \mathrm{a}$ \\
\hline $3: 1$ & 5.23 & $28.6 \mathrm{bc}$ & $1.44 \mathrm{e}$ & $298.3 \mathrm{~g}$ & $40.4 \mathrm{~g}$ & $119.3 \mathrm{a}$ & $143.8 \mathrm{a}$ & $24 \mathrm{a}$ \\
\hline $2: 1$ & 5.16 & $31.1 \mathrm{a}$ & $1.56 \mathrm{a}$ & $254.9 f$ & $47.1 \mathrm{~d}$ & 78.5abc & $149.7 \mathrm{a}$ & $44 a$ \\
\hline
\end{tabular}

part of sewage sludge and sawdust.

${ }^{\ddagger}$ Means followed by a common letter within a column are not significantly different by DMRT $(p<0.05)$.

\section{References}

Shrestha, S.L. 1996. Influence sewage sludge application on crop yields and heavy metal availability (MS Report on p. 212 Advanced soil Fertility).

Smith, S.R. 1996. Agricultural recycling of sewage sludge and environment, $\mathrm{CAB}$ International. UK. 